ISBN: 978-602-72362-7-1

\title{
EFEKTIVITAS KONSELING COGNITIVE BEHAVIOR TEKNIK SELF INSTRUCTIONAL TRAINING UNTUK MEREDUKSI PERILAKU MEROKOK
}

\author{
Zulfatul Laila ${ }^{1}$, Harwanti Noviandari ${ }^{2}$ \\ Fakultas Keguruan dan Ilmu Pendidikan, Universitas PGRI Banyuwangi \\ Email : zulfalaila.14@gmail.com ${ }^{1}$ \\ Email : hnoviandari83@gmail.com²
}

\begin{abstract}
Abstrak
Merokok merupakan suatu masalah di dalam masyarakat yang dapat menimbulkan banyak kerugian baik dari segi sosial ekonomi maupun kesehatan bahkan kematian.untuk mengatasi masalah tersebut, salah satunya melalui metode konseling. Tujuan utama penelitian ini adalah untuk menguji bagaimana keefektifan konseling cognitive behavior teknik self insctructional training dalam mereduksi perilaku merokok siswa kelas XI di SMK Gajah Mada Banyuwangi. Metode yang digunakan dalam penelitian ini adalah desain eksperimen dengan menggunakan rancangan control group pretest and posttest design. Sampel penelitian sebanyak 15 orang siswa yang memiliki kebiasaan merokok. Sampel ditentukan dengan teknik purposive sampling. Dalam penelitian ini analisis data menggunakan analisis data statistik (kuantitatif).
\end{abstract}

Kata kunci: Perilaku Merokok, Pelatihan Instruksi Diri

\begin{abstract}
Smoking is a problem in society that can cause much harm both in terms of socioeconomic and health and even death. To overcome the problem, one of them through counseling method. The main purpose of this study is to examine how the effectiveness of counseling Cognitive Behavior Self Insctructional Training techniques in reducing smoking behavior of grade XI students at SMK Gajah Mada Banyuwangi. The method used in this research is experimental design using control group design Pretest and Posttest design. The sample of study were 15 students who had smoking habit. The sample is determined by purposive sampling technique. In this study data analysis using statistical data analysis (quantitative).
\end{abstract}

Keywords : Smoking Behavior, Self Instructional Training.

\section{PENDAHULUAN}

Pelajar adalah generasi muda yang merupakan aset bangsa yang kelak akan menjadi generasi penerus dalam membangun bangsa. Suatu bangsa dapat maju jika generasi muda memiliki perilaku yang sehat sebab kesehatan mental seseorang akan mempengaruhi produktivitasnya. Sebagai generasi penerus bangsa, generasi muda harus menerapkan 


\section{FKIP Universitas PGRI Banyuwangi Seminar Nasional}

\section{Pendidikan Budaya dan Sejarah: "Dibalik Revitalisasi Budaya"}

ISBN: 978-602-72362-7-1

pola hidup yang sehat tersebut, salah satunya adalah tidak mengkonsumsi rokok.

Sebab, rokok berdampak negatif terhadap kesehatan. Akan tetapi, prevalensi perokok dari kalangan pelajar khususnya pelajar SMA cukuplah tinggi (Prasetiawan, 2016). Masalah perilaku merokok pada siswa dipengaruhi oleh beberapa faktor salah satunya adalah pengetahuan dan sikap. Pengetahuan yang rendah mengenai bahaya rokok akan menimbulkan sikap yang kurang perduli terhadap bahaya rokok, sikap yang kurang perduli terhadap bahaya rokok akan mendorong seorang siswa beperilaku merokok jika dipengaruhi oleh faktor-faktor yang mendorong mereka untuk merokok, misalnya adalah faktor pergaulan yang salah dan faktor iklan rokok yang terus muncul dilakukan oleh produsen rokok (Prasetiawan, 2016). Menurut Muhtar (dalam Sulistiawan, 2010) Kebiasaan merokok sering dikaitkan dengan terjadinya penyakit paru obstruktif menahun (PPOM). Namun kebiasaan merokok di negeri ini tetap tidak bisa dihilangkan, bahkan semakin meningkat. Sebagian besar penduduk di sejumlah negara mengurangi konsumsi mereka terhadap rokok, orang Indonesia justru malah sebaliknya. Indonesia kini menempati ranking ke-4 sebagai negara dengan jumlah perokok terbesar di dunia setelah Amerika Serikat, RRC dan Jepang. Tidak kurang dari $70 \%$ penduduk Indonesia kini jadi perokok aktif dan ironisnya lagi, sekitar $13,2 \%$ perokok di Indonesia adalah remaja berusia 15-19 tahun.

Fenomena merokok di Indonesia memang sudah sangat memprihatinkan dan kini sudah merambah ke anak-anak sekolah. Memang pada era modernisasi (gaya hidup modern) saat ini berdampak positif bagi kehidupan, seperti diperolehnya kemudahan-kemudahan dalam berbagai bidang, namun ternyata telah melahirkan dampak-dampak yang kurang menguntungkan, yaitu dengan munculnya berbagai problem yang semakin kompleks, baik yang bersifat personal maupun sosial (dalam Swarafika, 2017). Menurut Muhtar (dalam Sulistiawan, 2010) Banyak dijumpai di sejumlah tempat seperti warung nasi, terminal atau tempat-tempat nongkrong, sering dijumpai sekumpulan siswa berseragam putih biru (SLTP) atau putih abu-abu (SLTA) bersenda gurau sambil berlomba "mengepulkan asap". Pada tahap pertama, mereka mungkin saja merokok karena pemberian teman. Namun setelah kecanduan, kebutuhan merokok pun meningkat dan bisa saja akibat desakan kebutuhan terhadap rokok malah 


\section{FKIP Universitas PGRI Banyuwangi Seminar Nasional}

Pendidikan Budaya dan Sejarah: "Dibalik Revitalisasi Budaya"

ISBN: 978-602-72362-7-1

mendorong sebagian siswa mengambil langkah salah, seperti membohongi atau menipu orang tua. Bahkan sangat mungkin karena demi rokok, ada di antaranya terjerumus pada tindakan kriminal seperti mencuri atau memeras.

Menurut data terbaru Global Youth Tobacco Survey (GYTS) 2014, terdapat 18,3 persen pelajar Indonesia sudah punya kebiasaaan merokok, dengan 33,9 persen berjenis laki-laki dan 2,5 persen perempuan. GYTS 2014 dilakukan pada pelajar tingkat SMP berusia 13-15 tahun. Data perokok rata-rata masyarakat Indonesia (usia 15 tahun ke atas) adalah sekitar 30 persen, artinya dengan bertambahnya umur maka persentase perokoknya terus meningkat. Menurut Prof. Tjandra Yoga Aditama, SsP(K), MARS, DTM \& H, DTCE, Kepala Badan Penelitian dan Pengembangan Kesehatan Kementerian Kesehatan, dalam keterangan pers yang diterima $\mathrm{CN}$ Indonesia, kita dapat menekan kebiasaan merokok pada kaum muda atau pelajar, maka kita dapat juga mengendalikan perokok pada dewasa. Peran guru sangat berpengaruh untuk mengurangi perilaku merokok peserta didik, dimana guru juga dilarang merokok di lingkungan sekolah agar siswa tidak meniru perilaku merokok tersebut (Swarafika, 2017).
Program penanggulangan merokok di lingkungan sekolah punya peran cukup besar. Tapi, ternyata 11,7 persen perokok siswa laki-laki dan 9,5 persen siswa perempuan sudah mulai merokok sejak sebelum usia 7 tahun. Hasil penelitian menunjukkan bahwa hampir separuh $(47,2$ persen) siswa perokok Indonesia ternyata sudah status adiksi, atau ketagihan. Hal ini ditunjukkan dengan mereka biasanya sudah ingin merokok pada saat pertama bangun tidur. Angka ini tentu cukup memprihatinkan, karena mereka masih amat muda tapi sudah adiksi merokok (Swarafika, 2017). Permasalahan di atas apabila dibiarkan, maka akan menjadi permasalahan umum yang dilakukan oleh banyak siswa. Tentunya bisa menimbulkan rusaknya moral remaja Indonesia yang khususnya pelajar bisa mengakibatkan menurunnya kondisi kesehatan fisik dan menurunnya prestasi siswa yang dipengaruhi oleh perilaku merokok. Oleh karena itu diperlukan penanganan dalam upaya membantu siswa agar dapat meningkatkan kedisiplinan di sekolah. Upaya untuk menangani siswa yang bermasalah, khususnya yang terkait dengan pelanggaran disiplin sekolah dapat dilakukan melalui dua pendekatan yaitu: (1) Pendekatan disiplin; (2) Pendekatan bimbingan dan konseling. disinilah 


\section{FKIP Universitas PGRI Banyuwangi Seminar Nasional}

Pendidikan Budaya dan Sejarah: "Dibalik Revitalisasi Budaya"

ISBN: 978-602-72362-7-1

pendekatan yang kedua perlu digunakan yaitu melalui pendekatan Konseling Cognitive Behavior dengan Teknik Self Instructional Training. Menurut Aaron T. Beck (dalam Yahya AD, 2017) mendefinisikan CBT (Cognitive Behavior Therapy) sebagai pendekatan konseling yang dirancang untuk menyelesaikan permasalahan konseli pada saat ini dengan cara melakukan restrukturasi kognitif dan perilaku menyimpang. Konseling CBT adalah model teoritis yang menghubungkan pikiran dengan emosi dan perilaku. Proses konseling didasarkan pada konseptualisasi atau pemahaman konseli atas keyakinan khusus dan pola perilaku konseli. Harapan dari CBT yaitu munculnya restukturasi kognitif yang menyimpang dan sistem kepercayaan untuk membawa emosi dan perilaku dan perilaku ke arah yang kebih baik.

Menurut Corey (dalam Dewi, 2016) Salah satu teknik yang ada pada modifikasi konseling kognitif-perilaku adalah self instruction. Teknik self instruction merupakan salah satu teknik yang terdapat di dalam pendekatan cognitive behavior modification yang dikembangkan oleh Meinchenbaum. Menurut Baker \& Butler (dalam Dewi, 2016) Perilaku maladaptif dipengaruhi oleh pikiran irasional yang menyebabkan verbalisasi diri yang tidak tepat. Inti dari teknik adalah membangun kembali sistem kognisi konseli, namun terpusat pada pola verbalisasi overt (disuarakan secara lantang/ keras) dan covert (disuarakan dalam hati). Sedangkan menurut Jones (2011) self instructional training merupakan suatu usaha yang dilakukan oleh terapis atau konselor untuk melatih konseli agar dapat mengganti pernyataan negatif tentang dirinya dengan pernyataan positif berorientasi tugas yang memfasilitasi coping.

\section{KAJIAN LITERATUR DAN PENGEMBANGAN HIPOTESIS}

Menurut Gerald Corey (dalam Sofiany, 2016) Konseling perilaku (konseling behavior) adalah penerapan aneka ragam teknik dan prosedur yang berakar pada berbagai teori tentang belajar. Penerapan prinsip-prinsip belajar ini berakar pada teori pengkondisian klasik dari Ivan Pavlov maupun teori pengkondisian operan dari B.F. Skinner. Konseling Kognitif Perilaku, merupakan penggabungan teknik-teknik dari perspektif perilaku dengan teknik-teknik dari perspektif kognitif, karena dalam perkembangannya para praktisi teori konseling perilaku menyadari, adanya keterbatasan dalam teori-teori belajar dan 


\section{FKIP Universitas PGRI Banyuwangi Seminar Nasional}

Pendidikan Budaya dan Sejarah: "Dibalik Revitalisasi Budaya"

ISBN: 978-602-72362-7-1

mengakui peran kognisi, dalam mempengaruhi perilaku.

Menurut Aaron T. Beck (dalam Sofiany, 2016) mendefinisikan Cognitive Behavior Therapy (CBT) sebagai pendekatan konseling yang dirancang untuk menyelesaikan permasalahan konseli pada saat ini dengan cara melakukan restrukturisasi kognitif dan perilaku yang menyimpang. Pendekatan ini didasarkan pada formulasi kognitif, keyakinan dan strategi perilaku yang mengganggu. Proses konseling didasarkan pada konseptualisasi atau pemahaman konseli atas keyakinan khusus dan pola perilaku konseli. Harapan dari CBT yaitu munculnya restrukturiasasi kognitif dan system kepercayaan untuk membawa perubahan ke arah yang lebih baik.

Menurut Oemarjoedi (dalam Yahya, 2016) Tujuan dari konseling cognitive behavior yaitu mengajak konseli untuk menentang pikiran dan emosi yang salah dengan menampilkan bukti-bukti yang bertentangan dengan keyakinan mereka tentang masalah yang dihadapi. Konselor diharapkan mampu menolong konseli untuk mencari keyakinan yang sifatnya dogmatis dalam diri konseli dan secara kuat mencoba menguranginya.

Metode self instructional merupakan salah satu metode dari pendekatan

cognitive behavior, yang melibatkan identifikasi keyakinan-keyakinan disfungsional yang dimiliki seseorang dan mengubahnya menjadi lebih realistis serta melibatkan teknik-teknik modifikasi perilaku. Pada metode self-instruction ini, terdapat strategi-strategi kognitif yang bisa digunakan, seperti self-verbalization atau self-talk yang bertujuan untuk menuntun seseorang mengatasi masalah yang dihadapinya (Sayekti, 2017).

Sementara itu, teknik selfinstructional sendiri merupakan suatu teknik modifikasi perilaku yang memiliki dua kegunaan, yaitu untuk mengganti pemikiran negatif terhadap diri sendiri menjadi pemikiran yang positif serta dapat digunakan untuk mengarahkan perilaku.

Kegunaan metode self instruction untuk mengganti pemikiran negatif menjadi positif, didasari oleh pemikiran bahwa pandangan seseorang mengenai dirinya dapat diarahkan. Sementara itu, kegunaan teknik ini untuk mengarahkan perilaku didasari oleh pemikiran bahwa pemberian intruksi merupakan bagian penting pada perkembangan manusia dalam mengarahkan perilaku (Rock dalam Sayekti, 2017).

Menurut Kemenkes (dalam Sianipar, 2015) Perilaku merokok juga dapat didefinisikan sebagai perilaku yang 
membakar salah satu produk tembakau yang dimaksudkan untuk dibakar, dihisap, dan/ atau dihirup termasuk rokok kretek, rokok putih, cerutu atau bentuk lainnya yang dihasilkan dari tanaman cicotina tabacum, nicotina rustica dan spesies lainnya atau sintesisnya yang asapnya mengandung nikotin dan tar, dengan atau tanpa bahan tambahan.

Menurut Thahir (2016) secara umum tipe umum perokok dibagi dua, yaitu: 1) perokok aktif (Active Smoker) adalah seseorang yang benar-benar memiliki kebiasaan merokok. Merokok sudah enjadi bagian hidupnya, sehingga rasanya tidak enak bila saja tidak merokok; 2) Perokok Pasif (Passisve Smoker) adalah seseorang yang tidak memiliki kebiasaan merokok, namun terpaksa harus menghisap asap rokok yang dihembuskan oleh orang lain yan kebetulan ada didekatnya.

Penyebab remaja merokook antara lain sebagai berikut : 1) faktor individu meliputi pengaruh orang tua, pengaruh teman; dan 2) faktor psikologis.

Hipotesis yang dirumuskan dalam penelitian ini adalah Hipotesis I berbunyi, Konseling Cognitive Behavior teknik Self Instructional Training efektif untuk mreduksi perilaku merokok siswa kelas XI di SMK Gajah Mada Banyuwangi. Sedangkan Hipotesis II berbunyi, Terdapat perbedaan efektivitas antara kelompok eksperimen dengan kelompok control dalam mereduksi perilaku merokok siswa kelas XI di SMK Gajah Mada Banyuwangi.

\section{METODE PENELITIAN}

Pelaksanaan penelitian dilakukan di SMK Gajah Mada Banyuwangi. Populasi dalam penelitian ini adalah siswa-siswi kelas X IPS. Sebanyak 4 kelas yang berpartisipasi dalam penelitian ini yaitu kelas XI TKR 1,2,3 dan TSM 1. Jumlah sampel dalam penelitian ini sebanyak 15 siswa yang mengacu pada jumlah populasi yang memenuhi kriteria.

Metode pengumpulan data ini terdapat dua jenis metode pengumpulan data yaitu pengumpulan data utama dan metode pengumpulan data pelengkap, metode pengumpulan data utama berupa kuesioner yang akan disebar pada siswa sedangkan metode data pelengkap berupa obeservasi dan wawancara.

Metode penelitian yang pertama teknik analisis deskripif data instrumen perilaku merokok dianalisis secara deskriptif dan dinyatakan dengan jenjang kualifikasi. Jenjang kualifikasi dikategorikan berdasarkan skor rata-rata $(\bar{X})$, mean ideal (Mi), dan standar deviasi ideal (SDi). Setelah itu dilanjutkan dengan uji prasyarat yang terdiri dari uji normalitas dan uji homogenitas, dimana uji normalitas merupakan sebaran data dilakukan untuk meyakinkan bahwa data yang dihasilkan dalam penelitian benarbenar berditribusi normal, sehingga dapat dilakukan dan uji homogenits digunakan 
untuk mengetahui apakah kelompokkelompok sampel berasal dari populasi yang sama.

Bila uji prasyarat anarkis diatas telah dilakukan maka dapat dilnjutkn dengan hipotesis sebagai langkah lanjut dalam penelitian ini, dilakukan suatu prosedur analisis terhadap data-data yang diperoleh peneliti. Tujuan dari analisis data ini adalah mengungkapkan apa yang ingin diketahui dari penelitian ini. Dalam menganalisis data yang diperoleh selama melakukan penelitian, penulis menggunakan dua analisis statistik, antara lain (1) analisis statistik correlated data/paired sampel t-test dan (2) analisis statistik uncorrelated data/independent sampel t-test. Dasar pengambilan keputusannya adalah : (1)Jika thitung > t tabel, maka $\mathrm{H}_{0}$ ditolak; (2) Jika thitung $<\mathrm{t}$ tabel, maka $\mathrm{H}_{0}$ diterima Berdasarkan nilai probabilitasnya : (1) Jika probabilitas > 0,05 maka $\mathrm{H}_{0}$ diterima Jika probabilitas $<0,05$ maka $\mathrm{H}_{0}$ ditolak.

\section{RANCANGAN PENELITIAN}

Penelitian ini merupakan quasi experimental (eksperimen semu), dengan menggunakan rancangan Non Equivalent Pretest-Posttest Control Group Design. Rancangan control group design dipilih dengan pertimbangan bahwa dalam eksperimen semu,tidak memungkinkan untuk merandom subjek dalam kelompok populasi secara utuh. Selanjutnya pretest dan posttest berarti memberikan tes kepada subjek sebelum dan setelah perlakuan diberikan pada masing-masing kelompok. Rancangan ini dipilih karena penelitian ini merupakan penelitian terapeutik untuk mengetahui efektivitas atau pengaruh perlakuan terhadap variabel terikat. Artinya rancangan pretest dan posttest digunakan untuk mengetahui efektivitas konseling cognitive behavior teknik self instructional training untuk mereduksi perilaku merokok pada siswa kelas XI SMK Gajah Mada Banyuwangi.

\begin{tabular}{|c|ccc|}
\hline $\mathrm{E}$ & $\mathrm{O}_{1}$ & $\mathrm{X}$ & $\mathrm{O}_{2}$ \\
\hline $\mathrm{K}$ & $\mathrm{O}_{1}$ & - & $\mathrm{O}_{2}$ \\
\hline
\end{tabular}

(Sumber: Dantes, 2012:97)

Keterangan :

E : Eksperimen

K : Kelompok Kontrol

$\mathrm{X}$ : Konseling Cognitive Behavior dengan Teknik Self Intruction Training

: Konseling kelompok tanpa teknik khusus

$\mathrm{O}_{1}$ : Pengamatan awal, berupa pre-test sebelum diberikan perlakuan.

$\mathrm{O}_{2}$ : Pengamatan akhir, yaitu pemberian post-test setelah diberikan perlakuan. 


\section{HASIL DAN PEMBAHASAN}

Merokok merupakan suatu masalah di dalam masyarakat yang dapat menimbulkan banyak kerugian baik dari segi sosial ekonomi maupun kesehatan bahkan kematian.untuk mengatasi masalah tersebut, salah satunya melalui metode konseling. Tujuan utama penelitian ini adalah untuk menguji bagaimana keefektifan konseling cognitive behavior teknik self insctructional training dalam mereduksi perilaku merokok siswa kelas XI di SMK Gajah Mada Banyuwangi.

Menurut Jones (2011) self instructional training merupakan suatu usaha yang dilakukan oleh terapis atau konselor untuk melatih konseli agar dapat mengganti pernyataan negatif tentang dirinya dengan pernyataan positif berorientasi tugas yang memfasilitasi coping.

Metode yang digunakan dalam penelitian ini adalah desain eksperimen dengan menggunakan rancangan control group pretest and posttest design. Sampel penelitian sebanyak 15 orang siswa yang memiliki kebiasaan merokok. Sampel ditentukan dengan teknik purposive sampling. Dalam penelitian ini analisis data menggunakan analisis data statistik (kuantitatif).

\section{Daftar Pustaka}

Dantes, Nyoman. 2012. Metode Penelitian. Yogyakarta: Penerbit Andi.

Dantes, Nyoman. 2014. Analisis dan Desain Eksperimen. Singaraja: Universitas Pendidikan Ganesha.

Dewi, F.A, Adi Atmoko, Triyono. 2016. Keefektifan Teknik Self-Instruction dalam Konseling Kognitif-Perilaku untuk Meningkatkan Efikasi Diri Sosial Siswa SMKN 2 Malang. (Online), Vol. 1, No. 4: 172-178 dipublikasikan pada situs http://journal2.um.ac.id/index.php/jk bk/article/view/611 diakses 25 Maret 2018.

Prasetiawan, P. 2016. Efektivitas Metode Konseling Terhadap Perilaku Merokok Pada Siswa SMA Negeri 17 Di Kecamatan Laeya Konawe Selatan Tahun Ajaran 2015/2016. (Online). Jurnal diplubikasikan pada situshttp://ojs.uho.ac.id/index.php/JIMK ESMAS/article/view/670 diakses 20 Maret 2018.

Sianipar, M. 2015. Pengertian Perilaku Merokok Remaja. (Online). http://repository.uin.suska.ac.id/6894/ 3/BABII\%.pdf diakses 01 April 2018.

Sayekti, E. 2017. Efektifitas Teknik SelfInstruction Dalam Mereduksi Stress Akademik Pada Siswa Kelas XI Ma Yarobi Kec. Grobogan, Kab. Grobogan Tahun 2016/2017. Salatiga : Institut Agama Islam Negeri (IAIN) skripsi dipublikasikan pada http://erepository.perpus.iainsalatiga. ac.id/1634/1/ENGGAR\%20SAYEKTI $\% 20 P A I \% 20 \%$

20111\%2011\%20132.pdf diaskes pada 28 Maret 2018.

Sofiany, N. 2016. Pegertian Konseling Kognitive Behavior. (Online), http://NenySofiany07.blogspot.co.id/ 2016/11/pengertian konselingkognitif-behavior.html diakses 26 Maret 2018.

Swarafika, G. 2017. Konseling Kelompok Pendekatan Behavioral Dengan Teknik Self-Management Dalam 
Upaya Mereduksi Perilaku Merokok Peserta Didik Kelas VIII SMK Gajah Mada Bandar Lampung Tahun Ajaran 2016/2017. Lampung: IAIN Raden Intan Lampung. Skripsi dipublikasikan pada situs http://reposity.radenintan.ac.id/1342 /1/Skripsi_Swarafika.pdf diakses 18 Maret 2018.

Thahir, A. 2016. Pendekatan Konseling Behavior Dengan Teknik Self Control Untuk Mengurangi Kebiasaan Merokok Pada Peserta Didik di SMA Negeri 13 Bandar Lampung. (Online), Vol. 3, No.1: 63-77 dipubliksikan pada situs https://ejournal.radenintan.ac.id/ind ex.php/konseli diakses 01 April 2018.

Yahya, 2016. Pengaruh Konseling Cognitif Behavior Therapy (CBT) Dengan Teknik Self Control Untuk Mengurangi Perilaku Agresif Peserta Didik Kelas Viii Di Smpn 9 Bandar Lampung Tahun Pelajaran 2016/2017. Jurnal, IAIN Raden Intan Lampung. (Online), Vol. 3, No. 2: 187-200 dipublikasikan pada http://ejournal.radenintan.ac.id/inde x.php/konseli/article/view/561/452 diakses 28 Maret 2018. 